\title{
Technology of Reconditioning with Hardening of Working Elements of Construction and Road Machines by Composite Coatings
}

\author{
Aleksandr Kolomeichenko ${ }^{1 *}$, and Nikolay Titov ${ }^{1}$ \\ ${ }^{1}$ Orel State Agrarian University named after N.V. Parakhin, 69 Generala Rodina str., Orel, 302019, \\ Russia
}

\begin{abstract}
The article gives the description of the developed technology of increasing wear resistance of working elements of national and foreign constructional and road machines by composite coatings, obtained on working elements cutting surfaces applying Carbo Vibro Arc Hardening method (CVAH). The technology includes the following basic operations: cleaning and fault detection of the working element, removal of the worn cutting element, compensating element production, its sharpening and welding, preparation of metal and ceramic paste for Carbo Vibro Arc Hardening method (CVAH) and its application, Carbo Vibro Arc Hardening method (CVAH) of the harden cutting surface of the working element. When hardening new working elements technological process operations connected with production and welding the compensating element is not performed. According to the carried out results the rational composition and component concentration of the paste that provides significant increase of working elements wear resistance.
\end{abstract}

\section{Introduction}

Working elements of construction and road machines (shovel teeth, drilling instrument crews, blades of autograders and bulldozers, ground threshing machines cutters, etc.,) while in operation are subjected to intensive impact and abrasive wear, and as a result, lose their working capacity very quickly [1-6]. In this regard wear decrease and as a result, increase of their wear resistance and lifetime is one of the main vital scientific problems for enterprises, which produce and operate this machinery.

Now, to increase wear resistance and lifetime of working elements of machines of different purpose, ceramic and metal and ceramic materials are the most advanced $[3,5,6]$. Ceramic materials display sufficiently high wear resistance in comparison with hard alloys but, ceramic plastic deformation because of impossibility to accumulate in it constituent plastic deformation significantly constrain its application for hardening working elements, operated under the conditions of considerable impact loadings. Metal and ceramic materials are composite material, which consist of metal and steel base (matrix) and includes in its composition ceramic components (oxides, carbides, nitrides, etc.). Matrix provides these

*Corresponding author: kolom_sasha@inbox.ru 
materials with the required impact strength, and ceramic components - high hardness and wear resistance. When machine-working elements hardening metal and ceramic materials are applied on their cutting surfaces in the coating form very often. At the same time, the majority of famous technologies of coating deposition from the given materials differ in complexity and expensiveness of the applied equipment, and they do not provide the possibility of hardening wide nomenclature of working elements of construction and road machines of different mass and configuration. For that reason, the investigations aimed at development of the formation of the composite metal and ceramic coatings on cutting surfaces of working elements, are vital today and actual and provide the solution of important economic problem to increase wear resistance of working elements of national and foreign construction and road machines.

The Carbo Vibro Arc Hardening method (CVAH) is a modern method of formation of the composite metal ceramic coatings, which to a large extent is deprived from the above mentioned disadvantages and which permits to increase sufficiently the wear resistance of the working elements cutting surfaces [7-12]. At the CVAH the metal ceramic paste, containing the metal matrix, hardening ceramic components and the material activating the arcing process (cryolite), is applied on the harden cutting surface. The dried paste is fused by applying vibrating carbon electrode of the special facility. During the electric arc combustion on the harden surface the composite metal and ceramic coating is obtained. However, now, the investigations of the theoretical and technological capabilities of the CVAH method are being continued and the questions connected with selection of rational composition of the metal and ceramic pastes for the CVAH are not examined in full.

\section{Material and methods}

Preliminary the carried out investigations allowed to establish that each of the component of the metal ceramic paste for the CVAH considerably influences on the thickness and the physical and mechanical properties of the obtained with this method composite coating $[8,9,13,14,15]$. As a matrix of the metal ceramic pastes, we used the powder PR-NX17CP4 TU 14-22-33-90, produced by «Polema» (Tula). The selection of this powder as a matrix is because it is used for different types of welding deposition of wear resistant coatings on machine components of metallurgic, mining and power-producing equipment, road and agricultural machinery, extruder screws and other equipment. We used aluminum oxide Al2O3 GOST 8136 and boron carbide B4C GOST 5744 as ceramic components of the pastes. The ceramic components content in the paste composition was changed from 10 to $30 \%$. The content of cryolite Na3AlF6 GOST 10561 in all pastes composition was $10 \%$ [14-16]. The metal ceramic paste was prepared by mechanical mixture of the above-mentioned components with addition of a binding agent (water solution of glue PVA, then it was applied on the metal base from steel $65 \mathrm{G}$ and was dried until hardening. This steel trademark selection is provided with the fact that from this steel the majority of the working elements and many other machine components, which are operated in the conditions of the abrasive wear. The thickness of the paste deposited layer was variated from 1,0 to 3,0 mm.

For the CVAH we used installation VGDU-2, developed and manufactured by Federal State Budgetary Scientific Institution, Federal National Agricultural Center of All-Russian Engineering Institute (Moscow). The installation contains the inverter thyristor current source of $200 \ldots 250 \mathrm{~A}$, operating console and vibrator with embodied in it carbon electrode of diameter $6 \ldots 8 \mathrm{~mm}[9,11,14,15]$. During installation work between carbon electrode and hardened surface with the paste deposited layer, electric arc was ignited, as the result the composite coating was formed from the paste elements on the hardened surface. The CVAH was carried out on the following modes: current rate $-70 \ldots 75 \mathrm{~A}$, carbon electrode vibration 
was $25 \mathrm{~Hz}$. Carbon electrode vibration allows obtaining more toughen and solid composite metal ceramic coating and also decreasing working element heating during its hardening.

The investigations of the thickness and the microstructure of the obtained at the CVAH composite metal ceramic coatings were done on the cross-sections with the use of the autoemission scanning electronic microscope of super resolution Zeiss Ultra plus (Ultra 55). In the preparation of the cross-sections the samples at first were cut up by the high precision cutting-off machine «Minitom Struers», then they were located in the automatic electrohydraulic press «CitoPress-1 Struers», where they were pressed into resin. The ready-made disk with the samples was polished on the grinding-and-polishing machine «LaboPol-5 Struers» using emulsions until high luster.

Micro-hardness of the composite metal ceramic coatings, obtained at the CVAH, was determined on the cross-sections using the computerized micro-hardness tester PMT-3M-01 according to the method of Vickers at the load of $\mathrm{F}=1 \mathrm{H}$ and the exposure time of $\mathrm{t}=15 \mathrm{c}$. The number of the measurements was accepted such as to provide the required accuracy of the obtained results. The measurement of the obtained prints was done by viewing system connected to the personal computer. Statistical result analysis was carried out by the dedicated software by means of the automatic analysis of the image according to the hardness measurements standards.

\section{Theory}

We analyzed the theoretical backgrounds of formation of the qualitative composite metal ceramic coatings by the CVAH method earlier. The work [17] contains this information.

Scientific research complex allowed developing and proposing to engineering and maintenance production the technology of reconditioning with worn elements hardening or hardening of new working elements of national and foreign construction and road machines by composite coatings, which allows considerable increase of their lifetime. The proposed technology is versatile and allows reconditioning and hardening of working elements of wide nomenclature practically without limitation on mass and configuration. Its realization is possible in stationary conditions at specialized enterprises, dealing with production or maintenance of technique and in small workshops and even in field conditions at the presence of electric energy source. The application of the suggested versatile technology at manufacturing is particularly true from import substitution position at the spare parts market.

The suggested technology includes the following basic operations: cleaning, fault detection of working element, removal of the worn cutting part, production of compensating element and its sharpening with cutting edge formation, welding of compensating element, preparation and application of metal and ceramic paste, and its application, CVAH of cutting edge of the reconditioned working element. At hardening of new working elements, the technological process operations connected with manufacturing and welding of compensating element are not fulfilled.

Reconditioned working element cleaning is carried out using synthetic detergents of type Labomid or grinding machines and steel workshop brushes. At fault detection beamcompasses of type SHTS with precision of $0,1 \mathrm{~mm}$ and metal measuring rulers are used. To remove worn cutting part of working element is necessary to use angle grinders and cuttingoff grinding wheels. Usage of flame cutting at this technological operation is unfavorable because working element deformation can take place, burning of alloying elements, carbon, and structural change of basic material.

The compensating element intended to compensate working element cutting part wear, is produced from spring steel with hardness 35...40 HRC. As a material for producing compensating element, it is possible to use spring plates that have lost tension, but have hardness, which is at least equal to $35 \mathrm{HRC}$ [18]. Form and dimensions of compensating 
element in each specific case are determined depending on configuration and wear rate of working element. Then compensating element is tooled for the required angle with formation of cutting edge using universal tool grinder.

The compensating element is welded to the reconditioned working element, using thereat manual arc welding and electrodes of series UONI with diameter $3 \mathrm{~mm}$. Current rate at welding is $30 \ldots 140 \mathrm{~A}$, voltage $-50 \ldots 60 \mathrm{~V}$. Working element welding to working element being reconditioned before its hardening provides obtaining of welding joint of the better quality. It allows lifetime increase of reconditioned and hardened working elements in operation. After welding compensating element is subjected to CVAH with carbon electrode and composite metal and ceramic pastes.

Results / Discussion. The carried out investigations proved that the main influence on the thickness of hardening composite coating, obtained at CVAH, is produced with thickness of the deposited paste layer. Herewith at its increase the coating thickness also increases. But paste layer increase more than $2,5 \mathrm{~mm}$ is unreasonable, because in this case composite coating thickness begins to decrease. At paste layer thickness $2,7 \ldots 2,8 \mathrm{~mm}$ and more complete and high quality composite coating on the surface being hardened are not formed. It is connected with the fact that at sufficient thickness of paste layer the electric field intensity drops to the values at which it is not possible to ignite an arc.

With increase of matrix powder content in paste composition, the composite coating thickness increases too. Thereat, the maximum coating thickness $-1,0 \ldots 1,1 \mathrm{~mm}$ (Figure 1) was obtained on the pastes containing boron carbide, which provides the best ignition and arcing at CVAH.

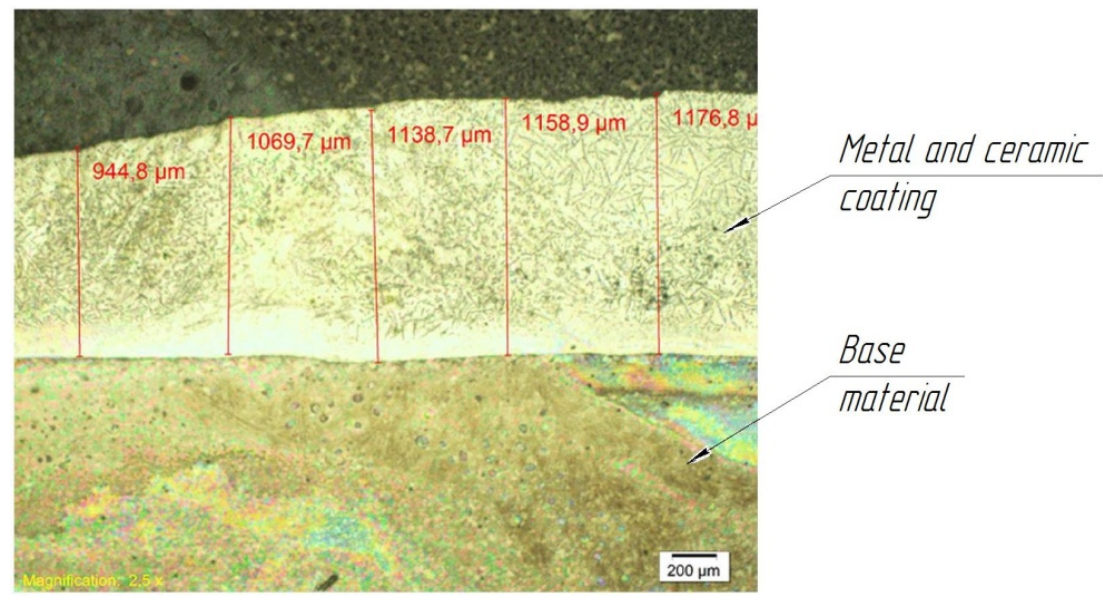

Fig. 1. Composite coating with thickness $1,0 \ldots 1,1 \mathrm{~mm}$, obtained at CVAH using the paste containing boron carbide.

The great influence on composite coatings microhardness is produced by ceramic paste components. Thereat with increase of their content in paste composite coatings microhardness increases too. At the same time, each of ceramic components produces different influence on coating microhardness. Thus, the largest mean of microhardness 1276 HV (corresponds to hardness $72 \mathrm{HRC}$ ) was displayed by the samples being hardened using the paste containing in its composition $30 \%$ of boron carbide. The carried out microstructure investigations have allowed to establish that the coating at this paste usage is composite material where hard-alloy particles (strengthening phases) are in the matrix of ferrum and nickel, they formed hard alloy Ni3Fe (spectrum S1 in figure 2) between them. Strengthening phases of coating are ferrum borides (Fe,Ni)2B and compound $\mathrm{FeCrB} 2$ (spectra S2 and S3 in figure 2). 


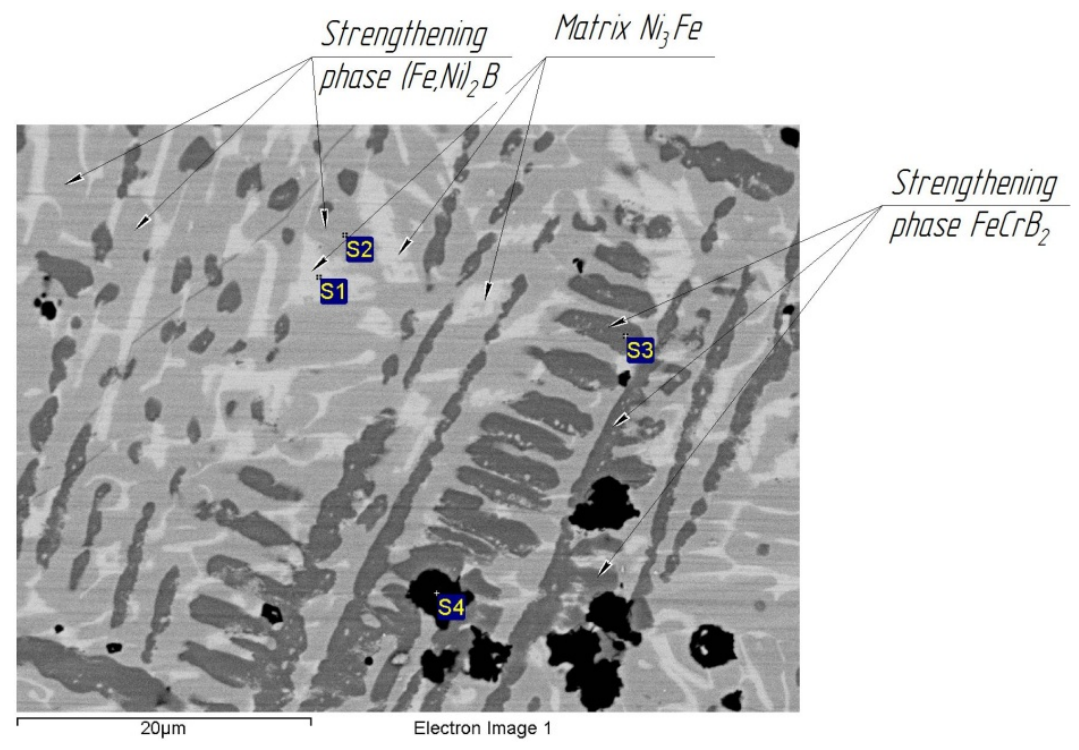

Fig. 2. Microstructure of metal and ceramic coating.

Differential characteristic of the obtained composite coating is the presence of definite porousness (spectrum S4 in figure 2). Pore appearance is connected firs, with the fact that $\mathrm{CVAH}$ is carried out in the air atmosphere, thus the protection of electric arc burning zone is absent.

\section{Conclusion}

Thus, the carried out investigations allowed to establish that for hardening of working elements of construction and road machines, the paste containing $60 \%$ of matrix powder ПРHX17CP4, 30\% boron carbide and 10\% of cryoliteis is the most rational. The results of comparison testing for wear of the samples hardened by this paste and unhardened samples from hardened steel $65 \mathrm{G}$ proved that after hardening their wear resistance increases on the average in 2,4 times (figure 3). In this connection, the usage of the paste with the same composition should allow to increase lifetime of working elements of construction and road machines considerably.

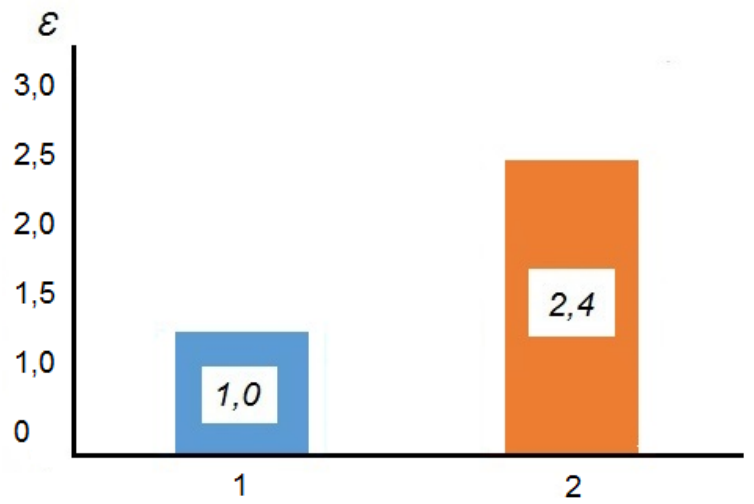

Fig. 3. Comparative wear resistance of unhardened (1) and hardened (2) with CVAH samples. 


\section{References}

1. A.M. Mikhalchenkov, V.P. Lyalyakin, A.A. Novikov, Elements lifetime increase of soil process machinery by means of thermohardening. Technology of metals, No 3 , pp. 43-48. (2015)

2. I.N. Kravchenko, N.I. Salyaev, S.I. Salyaev, (eds) Modeling of working elements wear processes of construction equipment of different design. Mechanization of construction, No 2, pp. 10-15. (2015)

3. V.I. Chernoivanov, V.P. Lyalyakin, I.G. Golubev, Organization and technology of machine elements reconditioning technology. Moscow: Federal State Budgetary Scientific Institution «Rosinformagrotech», pp. 568. (2016)

4. A.M. Mikhalchenkov, S.A. Solovyev, M.A. Mikhalchenkova, Efficiency of import substitution technologies of manufacturing, reconditioning and hardening of tillage equipment by means of compensating thermohardening elements. Hardening technologies and coatings, No 11, pp. 17-22. (2014)

5. I.N. Kravchenko, Yu.A. Kuznetsov, I.V. Sokolov, (eds) Plasma reconditioning and hardening of working elements of tillage and digging machines. Machinery and equipment for village, No 10, pp. 27-31. (2014)

6. V.P. Lyalyakin, V.F. Aulov, V.V. Ivanaisky, (eds) Peculiarities of inductive welding of long soil tilling elements of agricultural and road machines. Welding International, No 3, pp. 26-30. (2014)

7. N.V. Titov, A.V. Kolomeichenko, N.N. Litovchenko, Innovative method of tillage tool hardening. Vestnik OrelGAU, No 2, pp. 42-48. (2014)

8. V.P. Lyalyakin, N.V. Titov, N.N. Litovchenko, (eds) Carbo-vibro-arc method of hardening of machine elements operating in the conditions of abrasive wear, by means of metal ceramics welding. (CVANCW). Proceedings of State Scientific Research Technological Institute of Repair and Operation of Tractors and Agricultural Machinery. T.114. pp. 144-149. (2014)

9. G.R. Murtazin, B.G. Ziganshin, S.M. Yakhin, Increasing the resource of working bodies of tillage machines. Machinery and equipment for village, No 10, pp. 32-34. (2015)

10. N.V. Titov, A.V. Kolomeichenko, V.N. Logachev, I.N. Kravchenko, N.N. Litovchenko, Investigation of the hardness and wear resistance of working sections of machines hardened by vibro-arc surfacing using cermet materials. Welding International. Volume 29. No. 9, pp. 737-739. (2015)

11. S.N. Sharifullin, N.R. Adigamov, N.N. Adigamov, R.Y. Solovev, K.S. Arakcheeva, Surface hardening of cutting elements agricultural machinery vibro arc plasma. Journal of Physics: Conference Series, Volume 669, No 1, pp. 012049. (2016)

12. N.N. Litovchenko, V.N. Kulikov, N.V. Titov, Vibro arc surfacing by graphite electrode of nanometal ceramic composite materials. Welding International, No 2, pp. 51-53. (2013)

13. A.V. Kolomeichenko, N.V. Titov, Carbo-vibro-arc hardening is an advanced technique to increase lifetime at manufacturing and reconditioning of machine elements. The world of transport and technological machines, No 3, pp. 3-9. (2016)

14. A.V. Kolomeychenko, N.V. Titov, V.V. Vinogradov, A.M. Stolin, P.M. Bazin, The microstructure of composite cermet coatings produced by carbo-vibroarc surfacing. Welding International, Volume 31, No 9, pp. 739-742. (2017) 
15. N.V. Titov, A.V. Kolomeichenko, V.V. Vinogradov, (eds) Investigation of the influence of modes and parameters of carbo-vibro-arc hardening on metal ceramic coating thickness. Machinery and equipment for village, No 9, pp. 34-37. (2016)

16. A.V. Kolomeichenko, N.V. Titov, Yu.A. Kuznetsov, L.V. Kalashnikova, (eds) Investigation of nanometallokeramic composite coatings obtained by vibro-arc surfacing. IOP Conference Series: Materials Science and Engineering. pp. 012049. (2018)

17. A.V. Kolomeichenko, N.V. Titov, V.V. Vinogradov, Lifetime increase of A-blades of tillage equipment by metal ceramic coatings: monograph. Kursk: Publishers ZAO «University book», pp. 169. (2018)

18. A.M. Mikhalchenkov, M.A. Mikhalchenkova, A.A. Novikov, Utilization of decommissioned leaf springs at plow shares reconditioning. Tractors and agricultural machines, No 6, pp. 46-47. (2014) 